\title{
Fetal Intraventricular Hemorrhage in Open Neural Tube Defects: Prenatal Imaging Evaluation and Perinatal Outcomes
}

(D).A. Didier, (D).S. Martin-Saavedra, (DE.R. Oliver, (D).E. DeBari, (DL.T. Bilaniuk, (DL.J. Howell, (D).S. Moldenhauer, (D) N.S. Adzick, (D) G.G. Heuer, and DB.G. Coleman

\begin{abstract}
BACKGROUND AND PURPOSE: Fetal imaging is crucial in the evaluation of open neural tube defects. The identification of intraventricular hemorrhage prenatally has unclear clinical implications. We aimed to explore fetal imaging findings in open neural tube defects and evaluate associations between intraventricular hemorrhage with prenatal and postnatal hindbrain herniation, postnatal intraventricular hemorrhage, and ventricular shunt placement.
\end{abstract}

MATERIALS AND METHODS: After institutional review board approval, open neural tube defect cases evaluated by prenatal sonography between January 1, 2013 and April 24, 2018 were enrolled $(n=504)$. The presence of intraventricular hemorrhage and gray matter heterotopia by both prenatal sonography and MR imaging studies was used for classification. Cases of intraventricular hemorrhage had intraventricular hemorrhage without gray matter heterotopia $(n=33)$ and controls had neither intraventricular hemorrhage nor gray matter heterotopia $(n=$ 229). A total of 135 subjects with findings of gray matter heterotopia were excluded. Outcomes were compared with regression analyses.

RESULTS: Prenatal and postnatal hindbrain herniation and postnatal intraventricular hemorrhage were more frequent in cases of prenatal intraventricular hemorrhage compared with controls ( $97 \%$ versus $79 \%$, $50 \%$ versus $25 \%$, and $63 \%$ versus $12 \%$, respectively). Increased third ventricular diameter, specifically $>1 \mathrm{~mm}$, predicted hindbrain herniation (OR $=3.7[95 \% \mathrm{Cl}$, 1.5-11]) independent of lateral ventricular size and prenatal intraventricular hemorrhage. Fetal closure $(n=86)$ was independently protective against postnatal hindbrain herniation $(\mathrm{OR}=0.04[95 \% \mathrm{Cl}, 0.01-0.15])$ and postnatal intraventricular hemorrhage $(\mathrm{OR}=0.2[95 \% \mathrm{Cl}, 0.02-0.98])$. Prenatal intraventricular hemorrhage was not associated with ventricular shunt placement.

CONCLUSIONS: Intraventricular hemorrhage is relatively common in the prenatal evaluation of open neural tube defects. Hindbrain herniation is more common in cases of intraventricular hemorrhage, but in association with increased third ventricular size. Fetal closure reverses hindbrain herniation and decreases the rate of intraventricular hemorrhage postnatally, regardless of the presence of prenatal intraventricular hemorrhage.

ABBREVIATIONS: NTD = neural tube defects; BPD = biparietal diameter; GA = gestational age by sonography; IVH = intraventricular hemorrhage; $\mathrm{HC}=$ head circumference; $\mathrm{HH}=$ hindbrain herniation; $\mathrm{GMH}=$ gray matter heterotopia; ONTD = open neural tube defects; MMC = myelomeningocele; MS = myeloschisis; MOMS = Management of Myelomeningocele Study; $\mathrm{HC} / \mathrm{AC}=$ head circircumferenceto abdominal circumference ratio

$\mathbf{N}$ eural tube defects (NTD) can be classified as open (eg, myelomeningocele $[\mathrm{MMC}]$ and myeloschisis $[\mathrm{MS}]$ ) or closed, and detailed radiologic evaluation is key to their differentiation. ${ }^{1}$ Fetal sonography is effective in the assessment and characterization of NTD, with important implications for patient counseling and management. ${ }^{2-5}$ Fetal MR imaging provides supplementary

Received March 4, 2020; accepted after revision June 16

From the Departments of Radiology (R.A.D., J.S.M-S., E.R.O., S.E.D., L.T.B., B.G.C.), Center for Fetal Diagnosis and Treatment (R.A.D., E.R.O., S.E.D., L.T.B., L.J.H., J.S.M., N.S.A., G.G.H., B.G.C.), and Surgery (L.J.H., J.S.M., N.S.A., G.G.H.), The Children's Hospital of Philadelphia, Philadelphia, Pennsylvania; and Perelman School of Medicine (R.A.D., E.R.O., L.T.B., J.S.M., N.S.A., G.G.H., B.G.C.), University of Pennsylvania, Philadelphia, Pennsylvania.

Preliminary results previously presented at: Annual Meeting of the Society of Pediatric Radiology, May 3, 2019; San Francisco, California. or additional diagnostic information in these disorders. ${ }^{6}$ Both imaging modalities have similar performance in the evaluation of NTD prenatally ${ }^{5}$ and when compared with postnatal imaging. ${ }^{7}$

The association between open neural tube defects (ONTD) and hindbrain herniation $(\mathrm{HH})$ has long been described. ${ }^{8}$ In animal studies, surgically created MMC produced $\mathrm{HH}$ that could be reversed with prenatal repair. ${ }^{9,10}$ The Management of Myelomeningocele Study (MOMS) trial demonstrated clinical

Please address correspondence to Ryne A. Didier, MD, Children's Hospital of Philadelphia, 3401 Civic Center Blvd, Philadelphia, PA 19104; e-mail: didierr@email.chop.edu

Indicates article with supplemental on-line table.

http://dx.doi.org/10.3174/ajnr.A6745

AJNR Am J Neuroradiol 41:1923-29 Oct 2020 www.ajnr.org 

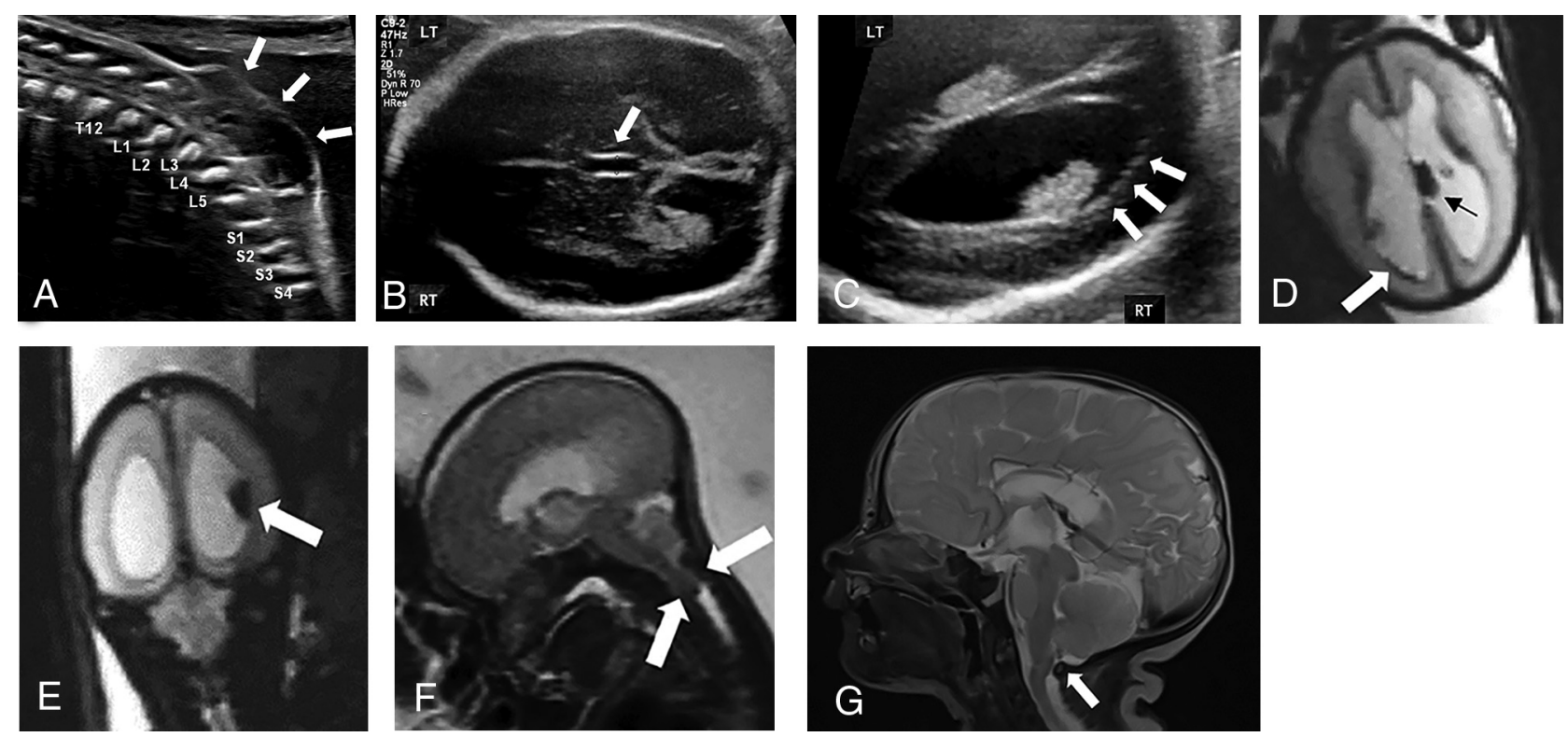

FIG 1. Prenatal intraventricular hemorrhage in open neural tube defect of a fetus ( 24 weeks and 2 days gestational age) with myelomeningocele and intraventricular hemorrhage with resolution of hindbrain herniation and intracranial blood products postnatally following in utero surgical closure. A, Sagittal grayscale sonography image of the fetal spine demonstrating the lumbosacral myelomeningocele (white arrows). Transverse gray-scale sonography images through the fetal skull demonstrate (B) dilation of the third ventricle measuring $2.8 \mathrm{~mm}$ in transverse dimension and (C) ependymal nodularity of the right lateral ventricle concerning for intraventricular hemorrhage. Corresponding fetal MR imaging demonstrates multiple foci of susceptibility artifact (D) within the left choroid plexus (black arrow) and along the right ventricular wall (white arrow) and (E) layering within the right lateral ventricle on axial and coronal EPI through the fetal brain, respectively, consistent with germinal matrix and intraventricular hemorrhage. F, Sagittal T2WI through the fetal brain demonstrates hindbrain herniation. Following in utero surgical closure at 25 weeks and 6 days gestational age, postnatal MR imaging performed at 3 days of age demonstrates (G) resolution of hindbrain herniation on sagittal T2Wl through the neonatal brain and there was no evidence of intraventricular hemorrhage on any sequence. RT, right; LT, left.

effectiveness $^{11}$ and further studies have supported these initial results. ${ }^{11-16}$ In the MOMS trial, the safety and efficacy of fetal closure was proved with slight outcome discrepancies in subsequent studies. ${ }^{17-20}$ Prenatal identification of $\mathrm{HH}$ is crucial for patient counseling and management and serves as an important outcome variable in conjunction with ventricular shunt placement. However, none of the reported studies have evaluated the significance of prenatal intraventricular hemorrhage (IVH) on these important outcomes. ${ }^{21,22}$

The incidence of IVH in ONTD has not been reported. This may be partially explained by the challenge in identification by both sonography and MR imaging. For example, sonography is less sensitive in detecting blood products and MR imaging may confuse normal germinal matrix vessels as hemorrhage, particularly on EPI sequences. Furthermore, imaging findings of IVH, including ependymal nodularity, overlap with those of gray matter heterotopia $(\mathrm{GMH})$, a common finding in NTD. The aim of this study is to investigate fetal sonography and MR imaging findings of patients with ONTD with attention to prenatal IVH to determine the incidence and its associations with prenatal and postnatal $\mathrm{HH}$, postnatal IVH, and ventricular shunt placement to better inform patient management and family counseling.

\section{MATERIALS AND METHODS}

\section{Setting}

As a large referral center for ONTD diagnosis and management, including fetal surgery, our institution evaluates approximately 100 new patients per year with this diagnosis. A single-institution retrospective case-control study was conducted after approval from our institutional review board. All patients who underwent evaluation for suspected NTD with fetal sonography at our institution between January 1, 2013 and April 24, 2018 were screened. Patients with a confirmed diagnosis of MMC or MS were included.

\section{Study Population and Case Selection}

Patients with discrepant diagnoses of the type of NTD (MMC or MS) between imaging modalities, those without fetal MR imaging, inconclusive $\mathrm{HH}$, or multiple congenital anomalies or chromosomal abnormalities were excluded. The presence or absence of IVH and GMH by both prenatal sonography and MR imaging studies was used for classification. Cases of IVH were determined by the presence of IVH and the absence of GMH by both modalities (Figs 1 and 2). Controls were defined as fetuses with neither IVH nor GMH $(n=229)$. Studies were excluded from final analyses if there was disagreement between imaging modalities of the presence or absence of IVH or the presence of GMH to maximize the true-positive rate of IVH. Ultimately, a total of 135 subjects with findings of GMH were excluded from the final analyses.

\section{Data Sources}

Data were extracted from electronic medical records. If imaging reports were incomplete, variables were unavailable, or if an inconsistency in the report was discovered (ie, dictation error), images were evaluated by a pediatric radiologist for resolution and to verify data accuracy. Report data were intentionally 

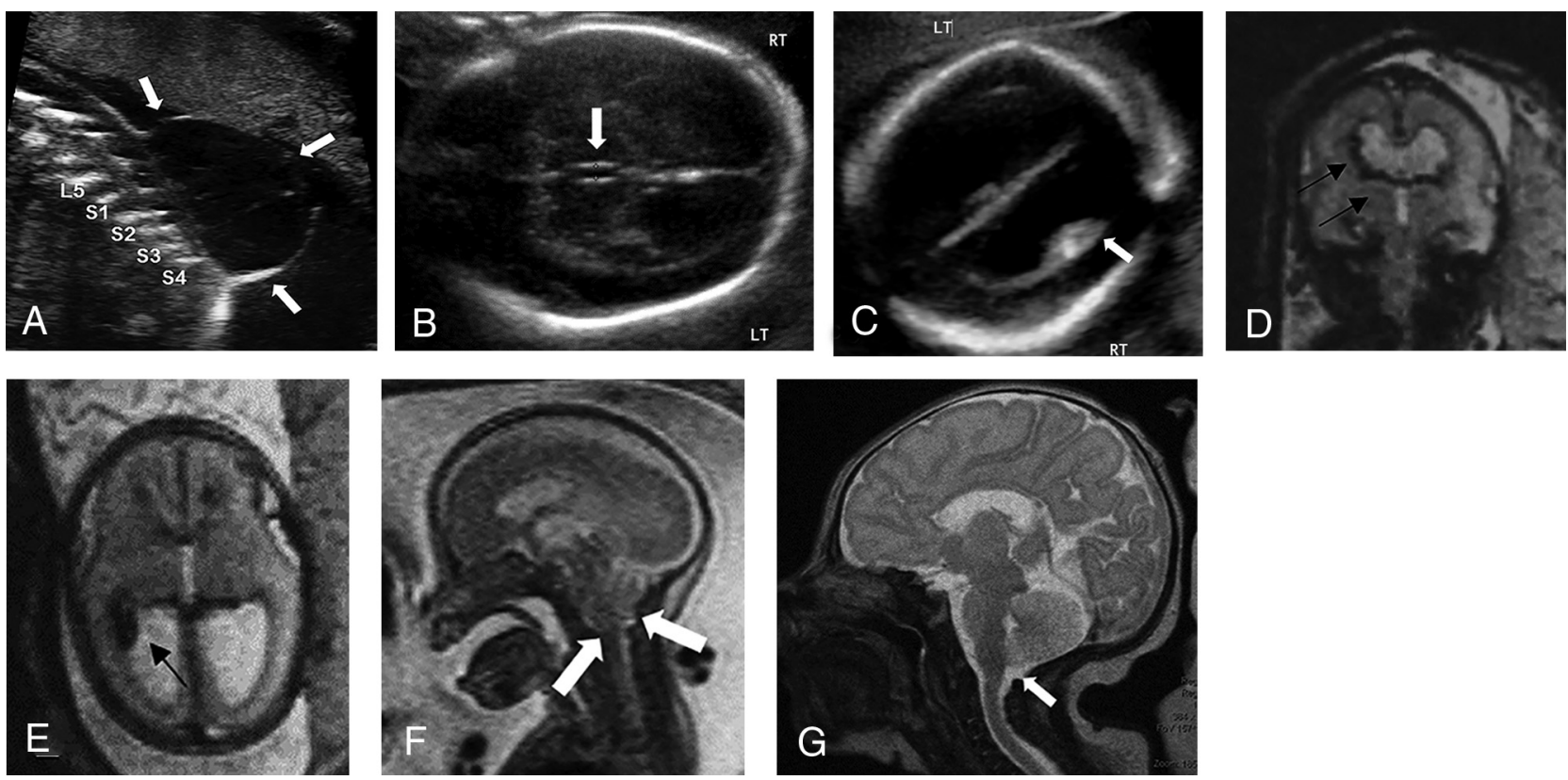

FIG 2. Prenatal intraventricular hemorrhage in open neural tube defect of a fetus ( 22 weeks and 3 days gestational age) with myelomeningocele and intraventricular hemorrhage with resolution of hindbrain herniation and intracranial blood products postnatally following in utero surgical closure. A, Sagittal gray-scale sonography image through the fetal lumbosacral spine demonstrates a myelomeningocele with a large, thin-walled sac. Transverse gray-scale sonography images through the fetal skull demonstrate (B) dilation of the third ventricle measuring $2 \mathrm{~mm}$ in transverse dimension and (C) layering echogenic material within the right lateral ventricle concerning for intraventricular hemorrhage. Corresponding fetal MR imaging demonstrates multiple foci of susceptibility artifact within the right lateral ventricle on (D) transverse and (E) coronal EPI through the fetal brain consistent with intraventricular hemorrhage. F, Sagittal T2WI through the fetal brain demonstrates hindbrain herniation. Following in utero surgical closure at 24 weeks and 5 days gestational age, postnatal MR imaging performed at 7 days of age demonstrates (G) resolution of hindbrain herniation on sagittal T2WI through the neonatal brain and there was no evidence of intraventricular hemorrhage on any sequence. RT, right; LT, left.

included in this retrospective study as it is the actionable information used to make critical treatment and management decisions during prenatal evaluation and consultation.

\section{Imaging Protocols}

Sonography and MR imaging examinations were performed per clinical protocols and before any surgical intervention. Detailed fetal sonography evaluation included transabdominal gray-scale and Doppler evaluation to assess the ventricular size, presence of ependymal nodularity, intraventricular debris/blood products, and the NTD. Transvaginal sonography was performed in all patients considering in utero fetal closure or for further anatomic evaluation of the brain and/or spine if transabdominal images were suboptimal. MR imaging examinations were performed on a $1.5 \mathrm{~T}$ or $3 \mathrm{~T}$ magnet using an 18-channel body coil in line with a spine coil with the following sequences: T2-weighted HASTE and steady-state free precession, and EPI performed in orthogonal planes through the fetal brain and spine. Postnatal MR imaging was performed with sequences including T2-weighted FSE, FLAIR, and CISS, T1-weighted FLASH or MPRAGE, gradientecho, spin-labeled perfusion imaging, and DWI.

\section{Variables and Study Outcomes}

Clinical data included: fetal sex, gestational age, ventricular shunt placement within 12 months of birth, type of pregnancy (singleton or multiple), presence of an additional anomaly, and age at the time of imaging studies and surgical interventions. Eligibility for in utero closure was determined by institutional protocol and in accordance with the MOMS trial criteria, and all were performed as an open procedure. ${ }^{11}$ Prenatal sonography data included: gestational age (GA) by sonography, biparietal diameter (BPD), head circumference (HC), head circumference to abdominal circumference ratio (HC/AC), cerebellar diameter, transverse third ventricular size, level of the osseous defect (T12 or higher, L1-L3, or L4 or lower), transverse lateral cerebral ventricles measurement at the level of the glomus of the choroid plexus, and absolute difference in lateral ventricular size (left versus right). Prenatal MR imaging data included: transverse measurement of the lateral ventricles at the level of the atria and absolute difference in lateral ventricular size. HH was defined as cerebellar tonsillar tissue below the foramen magnum on prenatal or postnatal MR imaging. Secondary outcomes were IVH by postnatal MR imaging (if performed $<30$ days of age and before surgical intervention) and requirement of ventricular shunt placement within 12 months of birth.

\section{Bias Assessment}

Patients were selected consecutively. All data were extracted by experienced research personnel using the Research Electronic Data Capture (REDCap) platform. Data were reviewed and validated by a board-certified radiologist with 3 or 8 years of experience. Concordance between prenatal imaging modalities identifying IVH was evaluated. Study personnel were blinded to postnatal findings of IVH at the time of data extraction and image review. 


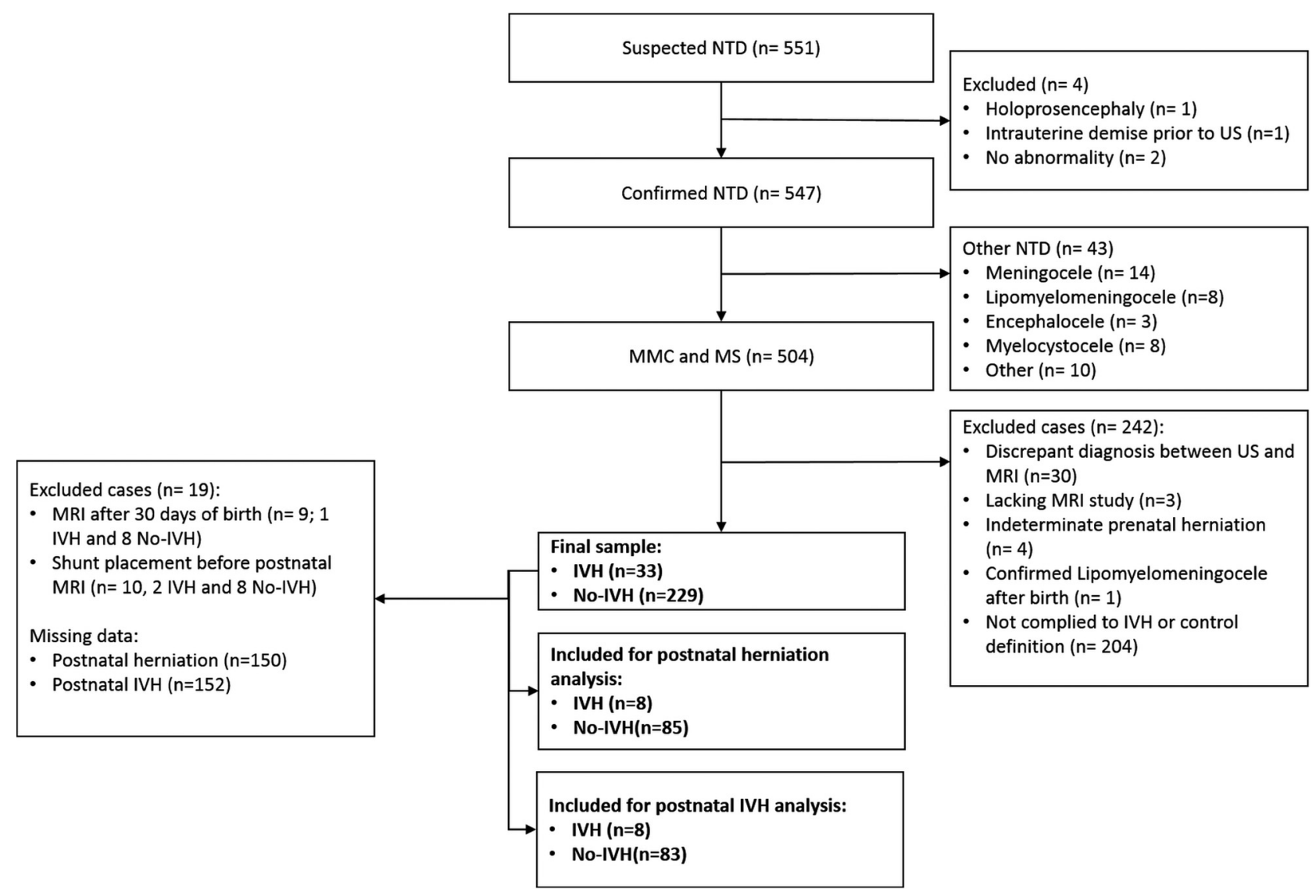

FIG 3. Population flow chart. US indicates sonography.

\section{Statistical Analysis}

R statistical software (version 3.5.1 for Windows, R Core Team) and packages 'vcd', 'aod', 'pscl', and 'ggplot2' were used. Cases and controls were compared using $\chi^{2}$ or Fisher exact test and independent $\mathrm{t}$ Student or Wilcoxon rank sum, as appropriate. Concordance was evaluated with Cohen $\kappa \cdot{ }^{23}$ Primary outcomes were evaluated using multivariate logistic regression models. Variables were included if univariate regression was significant (Wald test, $P<.05$ ), and McFadden pseudoR ${ }^{2}$ was used to determine effect size. Cut-points for significant continuous predictors were established using predicted probabilities and were included in an additional model as binary predictors. Analyses were considered significant at $P<.05$.

\section{RESULTS}

Five hundred four cases with confirmed MMC ( $n=369,73.2 \%)$ or MS $(n=135,26.8 \%)$ by prenatal sonography were included (Fig 3). Four hundred eighty-seven of 504 (96.6\%) also underwent fetal MR imaging. Overall, mean gestational age at prenatal sonography and MR imaging was 22 weeks and 4 days ( \pm 17 days), and mean maternal age was 29.75 ( \pm 5.37 ) years. IVH was reported prenatally in 83 of 504 (16.5\%) sonography and 108 of 487 (22.2\%) MR imaging examinations. Agreement between imaging modalities was observed in 404 of 487 cases (83\%). Of these, IVH was reported in 52 of 404 (13\%) $(\kappa=0.454$,
$P<.001)$. On postnatal MR imaging, IVH was reported in 38 of 223 (17.0\%) neonates. Compared with postnatal MR imaging, concordance with prenatal imaging modalities was lower but remained significant $(\kappa=0.131, P=.049$ and $\kappa=0.223, P=.001$ for fetal sonography and MR imaging, respectively).

The On-line Table compares the findings between IVH and controls. In cases of IVH, there was a higher prevalence of $\mathrm{HH}$, on both prenatal and postnatal imaging studies, though this only reached statistical significance prenatally $(P<.05)$. In cases of IVH, we found significantly increased bilateral lateral ventricular size $(P<.001)$, increased head biometric measurements $(P$ $<.001)$, and third ventricle diameter $(P<.001)$.

A multivariate model evaluating the association between prenatal IVH and $\mathrm{HH}$ was performed and included the presence of IVH, largest lateral ventricle by sonography, BPD, HC, GA, level of osseous defect, and transverse third ventricular diameter by sonography (Wald test, $\chi^{2}=31.8, P<.001$, pseudoR ${ }^{2}=0.27$ ). IVH was more common in prenatal $\mathrm{HH}$ but not independently predictive (OR $=3.1$ [95\% CI, 0.5-60]). Decreased BPD (OR = 0.02 [95\% CI, 0.001-0.37]), decreased HC ( $\mathrm{OR}=0.38$ [95\% CI, $0.16-0.89])$, increased GA (OR $=5.89$ [95\% CI, 2-19]), and increased third ventricular size ( $\mathrm{OR}=8.4$ [95\% CI, 2.2-37]) were predictive of prenatal $\mathrm{HH}$ (Table 1 and Fig 4). The level of the osseous defect was not shown to be predictive of $\mathrm{HH}$ in our cohort. After calculating cut-points, an additional multivariate logistic regression model showed good fit $\left(\chi^{2}=46.4, P<.001\right.$, 
Table 1: Coefficient results of multivariate logistic regression models for prenatal HH including continuous variable and categorical variables with cut-points

\begin{tabular}{|c|c|c|c|c|}
\hline Predicted Outcome & Predictor & $\beta$ & SE & $P$ \\
\hline \multirow[t]{6}{*}{ Prenatal HH (continuous variables) } & IVH presence & 1.6 & 1.1 & 1.6 \\
\hline & Right ventricular size by US (mm) & 0.1 & 0.1 & .08 \\
\hline & $\mathrm{BPD}(\mathrm{cm})$ & -3.6 & 1.5 & $.02^{\mathrm{a}}$ \\
\hline & Head circumference $(\mathrm{cm})$ & -1.1 & 0.4 & $.01^{\mathrm{a}}$ \\
\hline & $A \cup A$ & 1.7 & 0.6 & $.003^{\mathrm{a}}$ \\
\hline & Third ventricular diameter $(\mathrm{mm})$ & 2.5 & 0.7 & $<.001^{\mathrm{a}}$ \\
\hline \multirow[t]{4}{*}{ Prenatal HH (categoric variables with cut-points) } & $\mathrm{BPD}(>4.5 \mathrm{~cm})$ & -0.7 & 0.7 & .34 \\
\hline & $\mathrm{HC}(>18 \mathrm{~cm})$ & -1.2 & 0.7 & .1 \\
\hline & $\mathrm{AUA}$ (>21 weeks) & 0.6 & 0.7 & .44 \\
\hline & Third ventricle diameter ( $>1 \mathrm{~mm})$ & 1.2 & 0.4 & $.001^{\mathrm{a}}$ \\
\hline
\end{tabular}

Note:- $\mathrm{HH}$ indicates hindbrain herniation; IVH, intraventricular hemorrhage; mm, millimeters; $\mathrm{cm}$, centimeters; US, ultrasound; AUA, average ultrasound age; $\beta$, regression coefficient; SE, standard error.

a Significant difference $P<.05$.

pseudoR $\left.^{2}=0.07\right)$ (Table 1$)$. From this second model, only a third ventricular diameter $>1 \mathrm{~mm}(\mathrm{OR}=3.4$ [95\% CI, 1.77.5]) was independently predictive of prenatal $\mathrm{HH}$. Mean third ventricular size was higher in the setting of $\mathrm{HH}(1.15 \pm$ $0.74 \mathrm{~mm}$ versus $0.83 \pm 0.35 \mathrm{~mm} ; P<.001)$. A multivariate model evaluating variables associated with postnatal $\mathrm{HH}$ was performed and included: IVH, largest ventricular size by MR imaging, GA at birth, prenatal $\mathrm{HH}$, and history of in utero surgical closure (Wald test, $\chi^{2}=13.3, P=.02$, pseudoR ${ }^{2}=$ 0.31). Prenatal IVH was not predictive of postnatal $\mathrm{HH}$ $(\mathrm{OR}=2.8$ [95\% CI, 0.5-16]) (Table 2). Not surprisingly, prenatal $\mathrm{HH}$ predicted postnatal $\mathrm{HH}$ (OR 11.4 [95\% CI, 2.4$75]$ ), but a history of in utero surgical closure was negatively predictive $(\mathrm{OR}=0.04$ [95\% CI, 0.01-0.16]).

A final multivariate regression model showed that prenatal IVH was predictive (OR $=15.7$ [95\% CI, 2.8-80]) of postnatal IVH, while a history of in utero surgical closure (OR $=0.08$ [95\% CI, 0.01-0.39]) was negatively predictive (Wald test, $\chi^{2}=25.4, P<.001$, pseudoR ${ }^{2}=0.24$ ), suggesting that fetal closure is protective against persistent IVH. No association between prenatal IVH and postnatal ventricular shunt placement was observed (On-line Table).

\section{DISCUSSION}

IVH is commonly detected by sonography and MR imaging in prenatal evaluation of ONTD and frequently described on postnatal MR imaging. Prenatal IVH is associated with, but not independently predictive of, prenatal and postnatal $\mathrm{HH}$ likely related to its close association with increased ventriculomegaly. Third ventricular size was strongly associated and a $1 \mathrm{~mm}$ cut-point predicted prenatal $\mathrm{HH}$. Postnatal $\mathrm{HH}$ was associated with prenatal $\mathrm{HH}$ and history of fetal closure was negatively predictive. These findings confirm that in utero surgical closure reverses $\mathrm{HH}$, and we found that this outcome is independent of the presence of prenatal IVH. Last, prenatal IVH was not associated with a requirement for postnatal ventricular shunt placement.

Ventriculomegaly is a common finding in MMC and is thought to be secondary to obstruction of CSF by $\mathrm{HH}^{24-26}$ In cases of open NTD, associated $\mathrm{HH}$ is an important factor in determining eligibility for prenatal surgical intervention and contributes to predictions of patient outcomes. ${ }^{11,12,21,22} \mathrm{We}$ found an expected association between $\mathrm{HH}$ and decreased head biometric measurements as the $\mathrm{HH}$ limits normal calvarial expansion, which may serve as an additional clue to the presence of $\mathrm{HH}$. We also found an association between $\mathrm{HH}$ and increased $\mathrm{GA}$, suggesting that the progression of $\mathrm{HH}$ is possible later in gestation. Therefore, patients initially excluded from fetal surgery due to absent $\mathrm{HH}$ may benefit from follow-up evaluation for subsequent $\mathrm{HH}$ development.

In delineating the influence of prenatal IVH in our cohort, we found that ventricular size and head biometric parameters were significantly larger in cases of IVH, suggesting that hemorrhage may contribute to ventriculomegaly. Despite this association, we found that neither IVH nor increased lateral ventricular size was independently predictive of $\mathrm{HH}$, suggesting that ventriculomegaly is a consequence of $\mathrm{HH}$ rather than causative. Interestingly, third ventricular enlargement was strongly predictive and size $\geq 1 \mathrm{~mm}$ may be a more specific sign for $\mathrm{HH}$. While this measurement falls within the reported normal range for midgestation fetuses, ${ }^{27}$ these values are established from healthy fetuses without congenital anomalies and our data suggest that these normograms may not be applicable to our patient population and this is supported by our results demonstrating a smaller mean third ventricular diameter in cases without $\mathrm{HH}$. Therefore, sonography assessment of the third ventricle may aid in influencing the suspicion for $\mathrm{HH}$ and be of particular benefit when MR imaging is inconclusive or not readily available.

Importantly, our results demonstrate that prenatal IVH does not affect the efficacy of fetal closure in reversing $\mathrm{HH}$. While concordance for IVH detection was moderate prenatally and reduced postnatally, overall concordance remained statistically significant. These findings may be explained by the self-limited nature of IVH, time-associated factors, the potential for interval hemorrhage, and unavoidable differences in the timing of imaging. Our results are similar to those reported comparing prenatal and postnatal imaging studies for $\mathrm{GMH} .{ }^{28}$ In addition, our multivariate model shows that fetal closure may even promote IVH resolution; we suspect by reversal of $\mathrm{HH}$ and improvement in CSF flow dynamics thus allowing clearance of blood products. This is concordant 


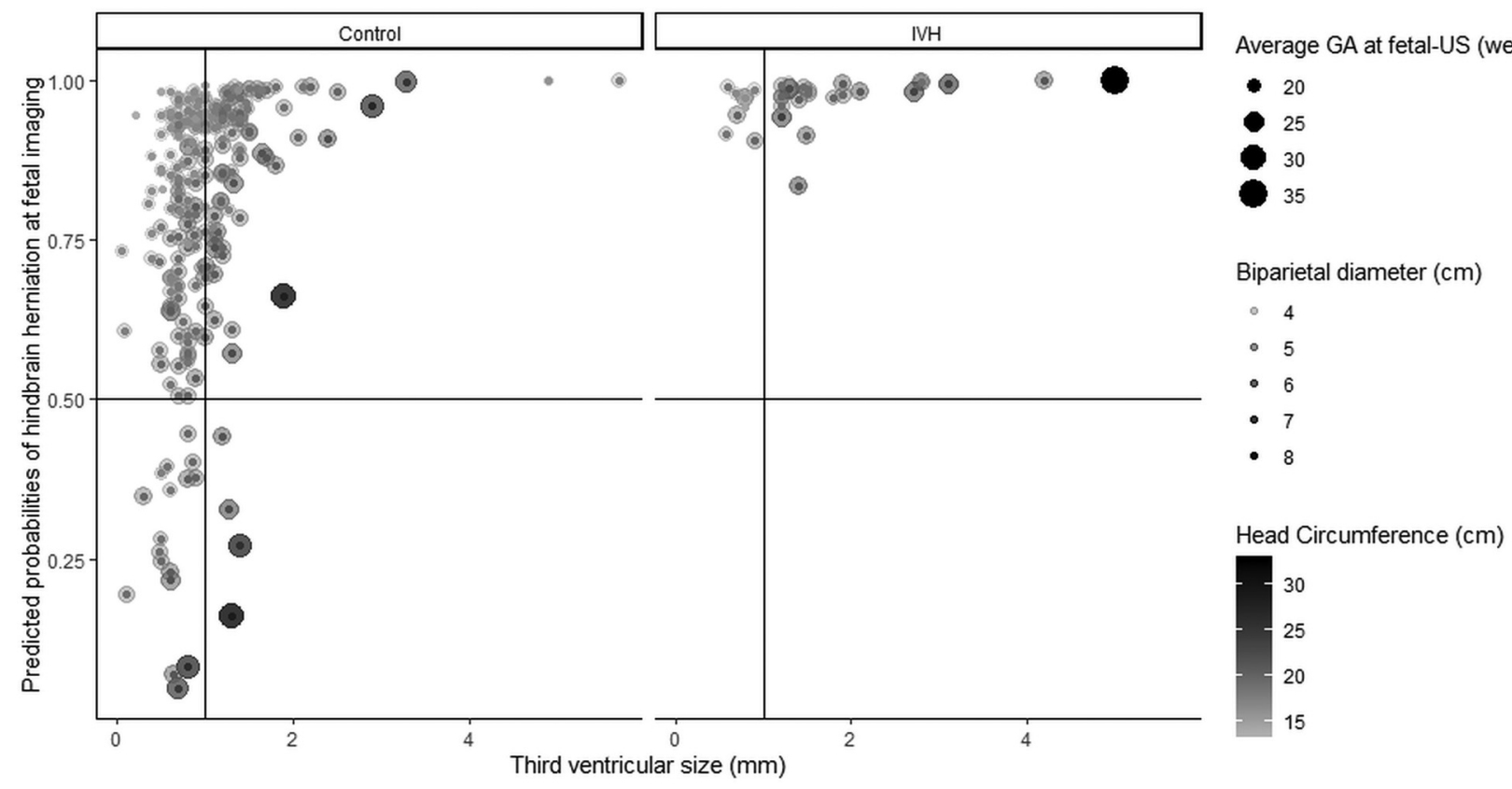

FIG 4. Effect of third ventricular diameter, biparietal diameter, and head circumference per study group according to logistic regression results. Scatterplots depicting the effect of the model described in Table 1 for controls (left) and cases of intraventricular hemorrhage (right). Y-axis shows the predicted probability for finding prenatal hindbrain herniation (horizontal line indicates the probability of $50 \%$ ). The $x$-axis shows the third ventricle diameter $(\mathrm{mm})$. The size of the geometric point corresponds to gestational age, color intensity illustrates head circumference, and transparency shows biparietal diameter for each subject. Most subjects with intraventricular hemorrhage had a third ventricle at or above $1 \mathrm{~mm}$ (vertical line), hence its strong predictive effect (Table 1).

Table 2: Coefficient results of multivariate logistic regression model for postnatal hindbrain herniation

\begin{tabular}{llccc}
\hline Predicted Outcome & \multicolumn{1}{c}{ Predictor } & $\boldsymbol{\beta}$ & SE & \\
\hline Postnatal HH & IVH presence & 1.0 & 0.9 & \\
& Largest ventricular size by MR (mm) & 0.11 & 0.1 & .23 \\
& GA at birth & -0.01 & 0.2 & .38 \\
& Prenatal HH & 1.8 & 0.7 & .86 \\
& Fetal closure & -3.2 & 0.7 & $<.007^{\mathrm{a}}$ \\
\hline
\end{tabular}

Note: $-\beta$ indicates regression coefficient; $\mathrm{SE}$, standard error.

a Significant difference $P<.05$.

with results reporting a higher prevalence of IVH in infants who did not undergo in utero surgery. ${ }^{21}$ Ultimately previously considered possible exclusion criteria, prenatal IVH should not preclude eligibility for in utero closure, and families should be counseled and treated accordingly.

The limitations of this study are the retrospective nature and decision to use imaging report data, though this accounts for variability in clinical practice. We ran concordance analyses among imaging studies before case classification and defined IVH based on findings by both sonography and MR imaging to account for this bias and increase data reliability. Previous studies have implemented a grading system in the severity of $\mathrm{HH}$, which would be of benefit for more detailed characterization, but the severity has not been shown to significantly change without fetal closure, does not influence patient counseling or management at our institution, and would be challenging to implement given the variability in the timing of postnatal MR imaging in our cohort; but could be a source of further study. Lastly, subtle changes in sonography and MR image acquisition over the study period may affect the study results, though performing statistical analyses as case-control series may decrease any potential influence on outcomes.

\section{CONCLUSIONS}

IVH is prevalent in the prenatal evaluation of fetuses with ONTD. While IVH is associated with prenatal HH, this is not independent and seen in conjunction with increased ventricular size. The transverse third ventricular diameter appears to be a good radiologic marker of prenatal $\mathrm{HH}$ and, if larger than $1 \mathrm{~mm}$, it is strongly predictive. The presence of prenatal IVH does not prevent resolution of $\mathrm{HH}$ following fetal surgical closure and does not increase the need for postnatal shunt placement. Overall, our results support that prenatal IVH in ONTD is selflimited, particularly in those with fetal closure that is protective against postnatal IVH, likely secondary to the restoration of CSF flow dynamics and clearance of blood products.

\section{REFERENCES}

1. Coleman BG, Langer JE, Horii SC. The diagnostic features of spina bifida: the role of ultrasound. Fetal Diagn Ther 2015;37:179-96 CrossRef Medline

2. Goldstein RB, Podrasky AE, Filly RA, et al. Effacement of the fetal cisterna magna in association with myelomeningocele. Radiology 1989;172:409-13 CrossRef Medline 
3. D'Addario V, Rossi AC, Pinto V, et al. Comparison of six sonographic signs in the prenatal diagnosis of spina bifida. $J$ Perinat Med 2008;36:330-34 CrossRef Medline

4. Pretorius DH, Russ PD, Rumack CM, et al. Diagnosis of brain neuropathology in utero. Neuroradiology 1986;28:386-97 CrossRef Medline

5. Araujo Júnior E, Nakano ML, Nardozza LMM, et al. Comparison between $2 \mathrm{D}$ ultrasonography and magnetic resonance imaging for assessing brain and spine parameters in fetuses with spina bifida. Arch Gynecol Obstet 2013;287:845-49 CrossRef Medline

6. Aertsen M, Verduyckt J, De Keyzer F, et al. Reliability of MR imaging-based posterior fossa and brain stem measurements in open spinal dysraphism in the era of fetal surgery. AJNR Am J Neuroradiol 2019;40:191-98 CrossRef Medline

7. Aaronson OS, Hernanz-Schulman M, Bruner JP, et al. Myelomeningocele: prenatal evaluation-comparison between transabdominal US and MR imaging. Radiology 2003;227:83943 CrossRef Medline

8. Variend S, Emery JL. Cervical dislocation of the cerebellum in children with meningomyelocele. Teratology 1976;13:281-89 CrossRef

9. Bouchard S, Davey MG, Rintoul NE, et al. Correction of hindbrain herniation and anatomy of the vermis after in utero repair of myelomeningocele in sheep. J Pediatr Surg 2003;38:451-58 CrossRef Medline

10. Paek BW, Farmer DL, Wilkinson CC, et al. Hindbrain herniation develops in surgically created myelomeningocele but is absent after repair in fetal lambs. Am J Obstet Gynecol 2000;183:1119-23 CrossRef Medline

11. Adzick NS, Thom EA, Spong CY, et al. A randomized trial of prenatal versus postnatal repair of myelomeningocele. $N$ Engl J Med 2011;364:993-1004 CrossRef Medline

12. Moldenhauer JS, Soni S, Rintoul NE, et al. Fetal myelomeningocele repair: the post-MOMS experience at the Children's Hospital of Philadelphia. Fetal Diagn Ther 2015;37:235-40 CrossRef Medline

13. Moldenhauer JS, Adzick NS. Fetal surgery for myelomeningocele: after the Management of Myelomeningocele Study (MOMS). Semin Fetal Neonatal Med 2017;22:360-66 CrossRef Medline

14. Heuer GG, Moldenhauer JS, Adzick NS. Prenatal surgery for myelomeningocele: review of the literature and future directions. Childs Nerv Syst 2017;33:1149-55 CrossRef Medline

15. Kabagambe SK, Jensen GW, Chen YJ, et al. Fetal surgery for myelomeningocele: a systematic review and meta-analysis of outcomes in fetoscopic versus open repair. Fetal Diagn Ther 2018;43:161-74 CrossRef Medline
16. Nagaraj UD, Bierbrauer KS, Zhang B, et al. Hindbrain herniation in Chiari II malformation on fetal and postnatal MRI. AJNR Am J Neuroradiol 2017;38:1031-36 CrossRef Medline

17. Bennett KA, Carroll MA, Shannon CN, et al. Reducing perinatal complications and preterm delivery for patients undergoing in utero closure of fetal myelomeningocele: further modifications to the multidisciplinary surgical technique. PED 2014;14:108-14 CrossRef Medline

18. Moron AF, Athanasiou A, Barbosa M, et al. Amniotic fluid lactic acid and matrix metalloproteinase- 8 levels at the time of fetal surgery for a spine defect: association with subsequent preterm prelabour rupture of membranes. BJOG 2018;125:1288-92 CrossRef Medline

19. Zaretsky MV, Liechty KW, Galan HL, et al. Modified hysterotomy closure technique for open fetal surgery. Fetal Diagn Ther 2018;44:10511 CrossRef Medline

20. Elbabaa SK, Gildehaus AM, Pierson MJ, et al. First 60 fetal in-utero myelomeningocele repairs at Saint Louis Fetal Care Institute in the post-MOMS trial era: hydrocephalus treatment outcomes (endoscopic third ventriculostomy versus ventriculo-peritoneal shunt). Childs Nerv Syst 2017;33:1157-68 CrossRef Medline

21. Zamłyński J, Olejek A, Koszutski T, et al. Comparison of prenatal and postnatal treatments of spina bifida in Poland-a non-randomized, single-center study. J Matern Neonatal Med 2014;27:1409-17 CrossRef Medline

22. Pedreira DAL, Zanon N, Nishikuni K, et al. Endoscopic surgery for the antenatal treatment of myelomeningocele: the CECAM trial. Am J Obstet Gynecol 2016;214:111.E1-111.E11 CrossRef Medline

23. Cohen J. A coefficient of agreement for nominal scales. Educ Psychol Meas 1960;20:37-46 CrossRef

24. Adzick NS. Fetal myelomeningocele: natural history, pathophysiology, and in-utero intervention. Semin Fetal Neonatal Med 2010;15:9-14 CrossRef Medline

25. Danzer E, Johnson MP, Adzick NS. Fetal surgery for myelomeningocele: progress and perspectives. Dev Med Child Neurol 2012;54:814 CrossRef Medline

26. Partridge EA, Flake AW. Maternal-fetal surgery for structural malformations. Best Pract Res Clin Obstet Gynaecol 2012;26:669-82 CrossRef Medline

27. Sari A, Ahmetoglu A, Dinc H, et al. Fetal biometry: size and configuration of the third ventricle. Acta Radiol 2005;46:631-35 CrossRef Medline

28. Nagaraj UD, Peiro JL, Bierbrauer KS, et al. Evaluation of subependymal gray matter heterotopias on fetal MRI. AJNR Am J Neuroradiol 2016;37:720-25 CrossRef Medline 